\title{
MINERALS: PROSPECTING, PROCESSING AND PRODUCTION
}

\author{
I. E. NeWNHAM \\ C.S.I.R.O. Division of Mineral Chemistry, P.O. Box 124, \\ Port Melbourne, Australia
}

\begin{abstract}
The application of chemistry to the technological requirements of the mineral industry is attended by problems of communication, isolation and application. Examples of research related to mineral exploration, underground fires, and the treatment of refractory ores suggest that the effective mineral chemist must learn the language of geology, metallurgy and engineering; that he must extend his science to include laboratory operations on a realistic scale; and that he must bridge the gap which separates the academic from the industrialist.

The encouragement which the mineral industry is prepared to give to imaginative chemists is illustrated by the worldwide programme of research on the treatment of McArthur River ore.
\end{abstract}

AN ARTICLE on minerals in the plenary programme of this Congress does more than reflect the popular Australian interest of the moment; it serves to remind chemists of a problem with a worldwide impact. Early in 1969, the Director of the United States Bureau of Mines reported to the House Committee on Interior and Insular Affairs: 'the capability of this nation to consume mineral raw materials is outstripping any foreseeable capability to meet its requirements at costs reasonably in line with current day costs ... We are not running out of resources; we are running out of the technology to exploit them'.

The nation which can put men on the moon is running out of the technology to exploit its mineral resources! The background to such an extraordinary claim is found in the Strategic Planning Programme of Mr O'Leary's Bureau ${ }^{1}$. Starting with the premise that mineral activities should be related to the national imperatives of maintaining security, assuring a sound economy and fostering social well-being, this Programme studies the present and projected flow of 81 mineral materials in the U.S.A. The history of each material is traced through nine stages-from the first step of exploration to the final act of re-use or disposal - in order to provide data for source, processing and end-use patterns. Supply-demand relations are then projected to specified points of time in the light of possible future changes, both technological and non-technological.

This sort of prophetic exercise draws attention to areas of uncertainty which are found to be related, in one or more ways, to eight situation factors-governmental, international, geographical, physical, technological, source 


\section{E. NEWNHAM}

and use patterns, environmental, and investment capital. In a comprehensive chart, the Bureau has listed 611 points at which these situation factors interact with the nine stages of mineral development to provide areas of uncertainty which must be resolved in the next decade. Of this impressive array of problems, 211 are technological.

An increasing number of chemists is being attracted by this field of technological uncertainty, and many are finding themselves confronted by problems which bear little relation to the normal practice of their profession. This article is addressed to this group.

\section{PROSPECTING, AND THE PROBLEM OF COMMUNICATION}

The widespread application of atomic absorption spectrophotometry has resulted in increasing use of soil analysis, stream analysis, air analysis, or even vegetation analysis as a means of geochemical reconnaissance in mineralized areas. Conscious that most of the deposits which could have been located easily from a simple examination of the earth's surface have already been discovered, the geologist is ready to study any anomalous or unusual property of a terrain in his search for concealed mineral deposits ${ }^{2}$. As a result the chemist's traditional mineral role of assayer and analyst is extending into unexpected fields of study. For example, geochemists in the U.S. Geological Survey have recently found that the distribution of anomalous amounts of mercury in soil gas (i.e. air collected at ground level) correlates well with the distribution of gold-bearing rocks covered by as much as 100 feet of gravel. The nature of the overburden, its thickness, and even its mercury content show little relation to the mercury content of the soil gas which does, however, display a diurnal variation inversely dependent on barometric pressure ${ }^{3}$.

What is the scientific explanation of such a phenomenon? Where is the inexhaustible supply of mercury vapour and what is its relation to a gold deposit? Is there a chemical principle involved which can point to the location of deposits with no recognizable outcrops, the geologist's so-called 'blind' ore-bodies? The chemist who seeks answers to these questions will be confronted by an even greater problem. How can he come to grips with theories of ore formation? From the earliest moment of geological speculation, few ore deposits have lacked vigorous supporters for two or more different origins. The resultant conflict has been called 'guerrology', and J. D. Ridge has recently listed 162 geological papers as required reading for the scientist who wishes to be informed of current additions to and modifications of the theories of ore formations.

Chemists may be encouraged to study the jig-saw of complexities which constitute the pattern of ore-genesis by a recent change in approach of many mining geologists to this problem. In place of the long-accepted belief that ores were introduced from a deep-seated hydrothermal magmatic source, they are giving increasing support to the theory that base and precious metal deposits could have been emplaced at the same time as, and shared a common origin with, their enclosing host rocks ${ }^{6}$. The corollaries to such an approach are that an ore may be related to its environment, and that a knowledge of the processes of ore genesis may lead to a more accurate recognition of the areas in which ores are located. 
In Australia this trend commenced in 1953. In a paper which is claimed to have electrified the geological world ${ }^{7}$, King and Thomson dissented from the accepted concept that the Broken Hill deposits, one of the greatest known concentrations of lead, zinc and silver in the earth's crust, had their origin in a deep-seated magmatic source of ore solutions ${ }^{8}$. In a subsequent lecture H. F. King said: 'The hydrothermal magmatic concept denied geologists the opportunity of considering what chemical events ... could have led up to the formation of ore deposits. Chemistry, it seems, was only involved where convenient; otherwise it was ignored' 9

Today, no chemist will be ignored who can contribute useful answers to such questions as:

(a) From what source could the metals have been derived?

(b) How were they transported?

(c) How were they concentrated to an ore grade?

(d) What environment was responsible for the deposition of the ore?

As early as 1954, the Australian Bureau of Mineral Resources sought to awaken chemists to their potentially important role by sponsoring work in the University of Sydney on the adsorption of metallic ions on natural adsorbents; this was supplemented by a study of precipitated metal sulphides in the Bureau's Canberra laboratories.

The results of this work at least demonstrated that alternatives to the conventional hydrothermal magmatic theory could not be ignored. For example, Roberts prepared the mineral chalcopyrite $\left(\mathrm{CuFeS}_{2}\right)$ at room temperature from co-precipitated sulphides of iron and copper. He then mixed this chalcopyrite with freshly precipitated zinc sulphide and kaolinite, and subjected the mixture to a pressure of 1000 atmospheres for 60 days at $130^{\circ}$ to $155^{\circ} \mathrm{C}$; the resultant specimens had textures which were remarkably similar to those of mineral samples traditionally classified as hydrothermal in origin. He created an 'emulsion' exsolution texture at a temperature several hundred degrees below that postulated by the hydrothermal theory, and his 'replacement' structure was produced by the interaction of sulphides which had been co-precipitated ${ }^{10}$.

The Bureau subsequently joined forces with the C.S.I.R.O. and the Australian Mineral Industries Research Association (A.M.I.R.A.) to establish the Baas Becking Laboratory ${ }^{11}$. This group has recently attempted to simulate conditions which could give rise to finely banded sulphide-rich zones such as those which occur in the McArthur River deposit of northern Australia. Working with solutions containing millimolar quantities of metal ions, Bubela and McDonald have studied the deposition of sulphides on a layer of $5 \mu$ diameter glass beads separating the solution from an underlying sulphide source. At room temperature $\mathrm{ZnCl}_{2}$-glass bead- $\mathrm{Na}_{2} \mathrm{~S}$ and $\mathrm{CuCl}_{2}-$ glass bead- $-\mathrm{Na}_{2} \mathrm{~S}$ systems gave stable bands of metal sulphide on which no further precipitation occurred even though metal and sulphide ions were still present. When an equal amount of glass beads was added to either system, a second set of characteristic bands developed above the first zone within two days, and these became stabilized in their turn ${ }^{12}$. In an extension of this work, similar results were obtained when McArthur River shales replaced the glass beads. There has been speculation about the type of change in the natural chemical environment which could have produced some of the 


\section{E. NEWNHAM}

mineral structures in this area and these workers suggest that sporadic periods of fine particulate sedimentation might be responsible for closelyspaced sulphide-rich bands of this kind.

The study of ore formation took a dramatic turn in 1964 with the discovery of the first contemporary example of the concentration of ore metal on the floor of the Red Sea. At a depth of 2000 metres, there are three huge reservoirs of saturated ore-forming brines in which the chloride content is eight times the comparable level in sea-water. The associated bottom sediments have the highest contents of zinc, copper and lead yet found in marine environments; the 1-metre thick, 20 million ton 'sulphide' zone, which exists below the Atlantis II deep, has average content of 11.1 per cent $\mathrm{ZnO}$ and 4.6 per cent $\mathrm{CuO}^{13}$. In a comprehensive review of the implications of these discoveries, D. E. White ${ }^{14}$ has drawn attention to an urgent need for experimental studies on metal solubilities in $\mathrm{Na}-\mathrm{Ca}-\mathrm{Cl}$ brines, and has presented chemists with an interesting series of problems involving (a) metal-sulphide complexes, and (b) metal-chloride complexes of differing stability in the presence of sulphide.

There is no lack of encouragement for the chemist who is prepared to master the difficult art of communicating with his geological colleagues. Commending the experimental work which has already been done on the original formation and emplacement of mineral deposits, R. L. Erickson, Geologist in charge of Exploration Research, U.S. Geological Survey, recently claimed that one of today's greatest needs was for top talent to be brought to bear on the chemical and mineralogical changes and the controls of those changes that have occurred since emplacement.

\section{PROCESSING, AND THE PROBLEM OF ISOLATION}

A criticism which may confront the ore genesis chemist is the remoteness of his laboratory from field work. This is just a particular example of a wide range of situations in which problems are not amenable to study on a laboratory basis only, and nowhere are such situations more evident than in the mining industry ${ }^{15}$. A typical example has been recently reported by Mount Isa Mines Limited ${ }^{16}$.

When production commenced in a leached zone of the 500 Copper orebody in 1963, ground temperatures were commonly of the order of $90^{\circ}$ to $100^{\circ} \mathrm{C}$ and several unexpected explosions resulted from misfires. On occasion local temperatures greatly exceeded the full-scale pyrometer reading of $260^{\circ} \mathrm{C}$ and, if a detonator were present, an explosion could occur with rapid escalation of temperatures to $800^{\circ} \mathrm{C}$ in some areas. By 1966, it was recognized that these unduly high temperatures were attributable to the combustion of pyrite and that the presence of chalcopyrite and pyrrhotite could significantly reduce the threshold temperature of this combustion reaction. Because the process responsible for raising the temperature of the pyrite to the ignition point had not been defined, the cooperation of chemists in Melbourne was sought in an effort to explain and, if possible, prevent this phenomenon.

It required some six months of coordinated work by geologists, chemists and mining engineers to demonstrate the unexpected influence of the ammonium nitrate-fuel oil (ANFO) explosive agent on pyrite at moderate 
temperature; and to show that a heap of ANFO-contaminated sulphide fines could deflagrate spontaneously, yielding hot cinders which would further spread the combustion. By combining laboratory techniques with field investigations, the chemists were able to define the three phases of the phenomenon at Mount Isa as :

(a) oxidation, accompanied by hydrolysis, of sulphides at ambient temperatures;

(b) ANFO-sulphide interactions ;

(c) combustion of mineral sulphides at elevated temperatures.

Realizing that little could be done to influence the already extensive phenomenon of natural oxidation and consequent heat build-up to $100^{\circ} \mathrm{C}$, Lukaszewski ${ }^{17}$ discovered that the addition of five to ten per cent of a selected borate and a half to one per cent of urea could chemically stabilize the ANFO against sulphide contamination at $150^{\circ} \mathrm{C}$. He was also able to suppress the combustion process significantly by the application of $3 \mathrm{wt} \%$ of selected phosphates and borates, either as a dry powder or as a solution containing one to two per cent of non-ionic surfactant.

The end result of this chemical study, conducted against the background of a specific mining environment, has been a series of investigations of the oxidation of mineral sulphides at ambient temperatures in other localities. It has opened an interesting field of laboratory research which can only be conducted effectively against the background of specific geographical environments.

Nowhere is the problem of isolation more evident than in studies based on the flotation plant; the extensive publications of experts such as Gaudin and Plaksin serve to emphasize the difficulty of relating laboratory results to plant practice. A novel approach to this problem has resulted from the decision of nine Australian mining companies to sponsor a study of the chemical properties of flotation pulps and their relation to flotation plant results. The investigators found no shortage of interesting parameters ${ }^{18}$. For example, it has long been recognized that oxygen has an important influence on the flotation of sulphides ${ }^{19}$, and it therefore seemed reasonable to monitor oxygen concentration as a first step towards establishing a suitable level of control. When the concentration in one particular flotation feed distributor was found to vary unpredictably between zero and 60 per cent of saturation, the cyclone overflow was aerated for eleven minutes prior to discharge into the distributor. The fluctuations diminished, but so also did the overall oxygen concentration! This is the type of chance observation, full of interest as regards both plant practice and laboratory studies, which can only originate when the chemist involves himself in the intricacies of plant operation.

A timely example of such an investigation is reported by Healy ${ }^{20}$. Commencing with the adsorption role of trivalent iron in flotation liquors, he lists ten subjects which are the most frequent topics of discussion among Australian operators in connection with metal ion activation. He then proceeds to demonstrate experimentally that very little adsorption of iron, or indeed of any other cation, will occur unless hydrolysis is 50 per cent complete, and that unwanted activation arising from adsorption can be avoided by $\mathrm{pH}$ control and by anionic complexing. The ultimate impact of 


\section{E. NEWNHAM}

this work on flotation practice awaits further studies with sulphide systems, but the example of sound academic work conducted against a background of plant practice is one which many chemists could emulate.

The industrial dividends from such work can be most rewarding. A recent survey has revealed that, if flotation plant performance could only be made to equal laboratory results, the increased annual productivity in Australia alone would be worth a conservative $\$ 15$ million.

\section{PRODUCTION, AND THE PROBLEM OF APPLICATION}

Possibly the mineral chemist's greatest problem is the selection of a project which has a reasonable chance of reaching industrial fruition. There is little to guide him in choosing the area in which he should work or the scale on which he should operate. Yet hindsight suggests that these choices should not be matters of chance. For example, the classic success story in the mineral industry of the 1960s is the Imperial Smelting Process--the culmination of a 50-year old metallurgical vision of continuous zinc production in a blast furnace. The chemical conditions which determined its effectiveness were defined by Maier and Ralston ${ }^{21}$ in 1926 when they studied the backreaction of zinc and carbon dioxide in the simple equilibrium

$$
\mathrm{ZnO}+\mathrm{CO} \rightleftharpoons \mathrm{Zn}+\mathrm{CO}_{2}
$$

Although these workers used molten tin to trap their reaction products, twenty five years elapsed before the development of the lead splash condenser proved one of the key factors in making the Imperial Smelting Furnace a working proposition. Hindsight suggests that a group of chemists, working in close contact with men who were familiar with blast furnace technology, could have shortened the time required for this particular discovery.

This over-simplified example is intended to draw attention to the barrier which separates the chemist from the metallurgical engineer. It compounds the problems of communication and isolation and it operates to the disadvantage of both parties. Consider its influence on the history of the TORCO process--the code name given by Anglo-American Corporation of South Africa Limited to a project for the Treatment of Refractory Copper Ore.

At the heart of the work lies an accidental 45-year-old discovery. One of the early methods for treating copper minerals which would not respond to normal flotation procedures involved heating the ore with a reducing gas at $300^{\circ} \mathrm{C}$, followed by ammonical leaching. In the course of work on the suitability of coal as a reducing agent it was noted that, at a temperature of $700^{\circ} \mathrm{C}$, the copper in a certain Chilean ore no longer remained disseminated through the gangue material, but formed metallic flakes on the surface of the coal; this copper-rich fraction could be collected by flotation.

Subsequent investigations showed that the phenomenon was due to the presence of 0.5 per cent sodium chloride in the mineral, and that the addition of a small amount of chloride to other minerals containing copper silicate or carbonate produced the same result. Less than one tenth of the chloride required to form cuprous chloride was involved in this reaction which provided a new cyclic route for the concentration of copper; it was named the 'segregation' process. 
Subsequent laboratory studies ${ }^{22,23}$ suggested that the mechanism of the process involved the formation of hydrogen chloride by hydrolysis of sodium chloride in the presence of siliceous gangue; reaction between the hydrogen chloride and copper in the ore to form the cuprous chloride trimer; and reduction of the chloride to metallic copper with regeneration of hydrogen chloride :

$$
\begin{aligned}
& 2 \mathrm{NaCl}+\mathrm{H}_{2} \mathrm{O}+\left[\mathrm{SiO}_{2}\right] \rightleftharpoons 2 \mathrm{HCl}+\left[\mathrm{Na}_{2} \mathrm{O} \cdot \mathrm{SiO}_{2}\right] \\
& 6[\mathrm{CuO}]+12 \mathrm{HCl} \rightleftharpoons 2 \mathrm{Cu}_{3} \mathrm{Cl}_{3}+6 \mathrm{H}_{2} \mathrm{O}+3 \mathrm{Cl}_{2} \\
& \mathrm{C}+\mathrm{H}_{2} \mathrm{O} \rightleftharpoons \mathrm{CO}+\mathrm{H}_{2} \\
& 2 \mathrm{Cu}_{3} \mathrm{Cl}_{3}+3 \mathrm{H}_{2} \rightleftharpoons 6 \mathrm{Cu}+6 \mathrm{HCl}
\end{aligned}
$$

The overall rate of this complex series of reactions proved surprisingly fast; if a mixture of malachite, silica and coal was heated at $750^{\circ} \mathrm{C}, 90$ per cent of the copper coated the carbon particles in ten seconds.

Despite intermittent attempts to develop the process over a period of thirty years, the first public discussion of this intriguing sequence of chemical reactions did not take place until 1960 when Pollandt and Pease described their attempts to segregate copper in a Peruvian ore ${ }^{24}$. The 20-page record of oral and written discussion which followed the presentation of their paper in London illustrates the lack of contact between the metallurgists and chemists. The authors referred to their uncertainty concerning the role of hydrochloric acid in the reaction, yet no one subsequently drew their attention to the work of Schäfer and Etzel ${ }^{25}$ who, in 1957, had discussed in detail the chemistry of copper transport. This work included a study of the competing effects of the exothermic reaction

$$
3 \mathrm{Cu}_{2} \mathrm{O}+6 \mathrm{HCl} \rightleftharpoons 2 \mathrm{Cu}_{3} \mathrm{Cl}_{3}+3 \mathrm{H}_{2} \mathrm{O}
$$

and the endothermic reaction

$$
\mathrm{Cu}_{2} \mathrm{O}+2 \mathrm{HCl} \rightleftharpoons 2 \mathrm{CuCl}+\mathrm{H}_{2} \mathrm{O}
$$

But if the metallurgists had not studied the chemical literature, it is also evident that the chemists were unaware of interesting developments which were taking place in the comparatively isolated mining areas of Chile, Mauretania, Peru and Rhodesia. Another 1957 reference to the cuprous chloride trimer reveals that, as early as 1950 , Pauling had postulated a metalmetal bonding configuration for this compound ${ }^{26}$. Yet no enterprising chemistry research student of that period attempted to relate the structure of the trimer vapour to the mode of deposition of copper in the segregation process.

When, in 1967, Pinkney and Plint finally published an account of the successful development of the TORCO process ${ }^{27}$, F. D. Richardson remarked that: 'all one could be sure of, insofar as the chemistry was concerned, was that the overall thermodynamics of the process was sound; that $\mathrm{HCl}$ gas was produced from sodium chloride and silica; and that volatile cuprous chloride was probably, but not certainly, the means whereby copper moved from its finely divided state in the ore to the carbon on which it deposited. There was no clear understanding of the reduction step or the kinetics of the 


\section{E. NEWNHAM}

whole series of consecutive reactions which were involved. If the segregation process was to be controlled and operated with a wide range of ores, a proper understanding of the chemistry was most important ${ }^{28}$.

But more is required of a chemist than the proper understanding of reaction mechanisms. The meeting of the Institution of Mining and Metallurgy which listened to E. T. Pinkney, also heard a comprehensive review of the early development of the copper segregation process by M. R. W. Rey who, for forty years, had maintained a vital and effective interest in its growth. Rey described how, when he worked with a 2.5 metre kiln and a 1.8 metre reactor, it was the poor feeding and mixing conditions and an inadequate combustion chamber, rather than chemical problems, which terminated the experiment. He enumerated the four stages which should precede the successful application of chemistry in the mineral industry as:

(a) laboratory work on the reaction;

(b) continuous laboratory operation on a realistic scale ;

(c) pilot plant;

(d) commercial plant which still has piloting connotation.

Reactions of the London audience to the Pinkney-Plint and Rey papers were predictable: they ranged from a plea for fundamental studies involving three $\mathrm{Ph} . \mathrm{D}$. students to a claim that the appraisal of economic potentials should precede laboratory studies. But for the chemist the message was clear; he was vitally concerned with the first two of Rey's four stages and the engineer with the last three. The application of chemistry could be impeded, not only by the problems of communication and isolation, but by a failure to establish effective interdisciplinary contact in the vital second stage of continuous laboratory operation on a realistic scale. Aspects of this theme have been developed by F. D. Richardson ${ }^{30}$; and the Anglo-American Corporation film 'Breakthrough' provides a working example of these principles in action. They are reiterated in this paper to remind the chemist that the rapidly growing field of mineral science draws indiscriminately on the skills of chemistry, physics and engineering.

\section{EPILOGUE-THE MCARTHUR RIVER PROJECT}

Lest the problems of the foregoing sections should daunt any potential mineral chemist, I conclude with a topical Australian example which illustrates how the mineral industry itself seeks to help the chemist overcome some of these difficulties.

In the 16th latitude of northern Australia, halfway between Mount Isa and Darwin, the McArthur River flows into the Gulf of Carpentaria; some 50 miles inland, although almost twice that distance by road, it passes over a 200 million ton deposit of zinc-lead ore. A small outcrop of this orebody was discovered in 1955.

Tests conducted at Mount Isa, and subsequent work by the American Smelting and Refining Company at El Paso, revealed that the extremely fine grain-size of the deposit militated against the production of the usual zinc and lead flotation concentrates. In 1963 Mount Isa Mines Limited (MIM) asked G. J. R. Burton, a director of the Company, to make a preliminary study of the problems, particularly those of a metallurgical nature, associated 
with bringing the deposit into production on an economic basis. He travelled widely in his search for information, but by the end of the year he could only recommend that all available resources, including the use of overseas laboratories, should be explored. He envisaged expenditure in excess of $£ 100000$.

The task of 'exploring avenues' was given to C. D. Williams who in 1964 took the problem of McArthur River to every sizeable group of chemists and metallurgists in the research laboratories of Australia; at the same time the Company spread the news through its overseas contacts. A programme of mineralogical and flotation studies was readily forthcoming. Drill core samples were used by MIM and by the Australian Mineral Development Laboratories (AMDEL), and a 100 -foot shaft was sunk to provide material for $100 \mathrm{lb}$ per hour test programmes. Subsequently this shaft was extended to $250 \mathrm{ft}$ with batches of ore going to Metallgesellschaft (Germany), DSIR (United Kingdom), Cyanamid and Galigher Corporation (USA), Mitsui (Japan), and Lakefield Research (Canada). The exploration camp at McArthur River became a popular stop-over point for overseas experts.

But the chemical programme was not so easily arranged. Apart from the C.S.I.R.O., only the University of Melbourne responded to Mount Isa's first plea for assistance; the University of Tasmania joined the programme some twelve months later. Conventional and unconventional approaches were also studied by the Colorado School of Mines Research Foundation, and the British Columbia Research Council. Undeterred by the limited range of novel ideas, MIM commissioned AMDEL in 1966 to survey all possible chemical approaches, feasible or otherwise, to the McArthur River problem. Of the ten projects subsequently recommended, all save one (which involved the uneconomic use of nitric acid) were subjected to laboratory tests. One result of the exercise was a further sponsored project in the University of New South Wales.

The $£ 100000$ estimate of G. J. R. Burton grew to an actual expenditure of $\$ 4.25$ million in five years, with almost $\$ 1$ million committed to research; it was certainly not MIM parsimony which confined University participation to only 20 per cent of the Chemistry Departments in Australia! To the best of my knowledge the Company's offer of research support is still open, and a portion of the 600 tons of ore mined in 1967 has been reserved for chemists with novel ideas.

One of the more fruitful chemical projects arose from a suggestion by MIM that the C.S.I.R.O. should investigate the possibility of using pressure leaching-a most radical departure for a smelting company. On the basis of his earlier experience with sulphide ores, T. R. Scott studied an acid oxidative leach at $110^{\circ} \mathrm{C}$ which would yield a zinc sulphate solution, and a residue comprising lead sulphate, elemental sulphur and gangue. Quite independently the Electrolytic Zinc Company of Australasia (EZ) developed a novel process for dissolving insoluble lead salts in an ammoniacal ammonium sulphate solution. In 1965, MIM broke new ground in the pattern of Australian chemistry by arranging a three-party agreement which linked their own research facilities with those of EZ and the C.S.I.R.O. in a joint investigation of the treatment of McArthur River ore. The consortium studied fourteen possible methods for treating various possible concentrates, and several overseas visits were made to ensure that nothing had been neglected. 


\section{E. NEWNHAM}

The research programme showed that two of the major problems would be the interference of iron and the recovery of lead. After four years work, sufficient laboratory data had been assembled in 1968 to justify placing a contract with engineering consultants for preliminary drawings of a possible process and the preparation of a tentative capital cost estimate. At the same time the project was ready for the second of Rey's four steps in the application of chemistry-continuous laboratory operation on a realistic scale. A fourstage series of titanium autoclaves was constructed in Melbourne and the resultant zinc liquor and lead residue forwarded to Risdon, Tasmania, for treatment in continuous electrolytic and extraction rigs.

Chemical events have confirmed the value of this phase of the investigation. In the course of laboratory batch work, it had been shown that the addition of potassium sulphate suppressed the solubility of iron and decreased the formation of lead jarosite by forming an insoluble potassium jarosite $\left(\mathrm{K}_{2} \mathrm{O} .3 \mathrm{Fe}_{2} \mathrm{O}_{3} \cdot 4 \mathrm{SO}_{3} \cdot 6 \mathrm{H}_{2} \mathrm{O}\right)$. However, similar additions in the continuous plant resulted in deposition of an adherent crystalline scale on all interior surfaces, and transfer lines were soon blocked. It would be difficult to predict the possible formation of this new compound, of empirical formula $\mathrm{K}_{2} \mathrm{O} .2 \mathrm{CaO} . \mathrm{ZnO} .4 \mathrm{SO}_{3}$, from laboratory tests; yet its unexpected appearance in a larger pilot plant could have resulted in expensive delays and modification. The simulation of a process on a realistic scale remains an indispensable part of the chemist's responsibilities.

During the current year, expenditure on the McArthur Programme will total $\$ 600000$ of which more than $\$ 200000$ will be devoted to research. A decision concerning the construction of a major pilot-plant will depend on the results obtained in the rigs which have been assembled in Melbourne and Hobart. For those involved in this operation, there remains the haunting question-is there a better approach?

No single problem of greater potential economic significance confronts Australian chemists; yet no paper having even a tenuous connection with the treatment of McArthur River ore is listed for discussion in the programme of this Congress. Are we paying sufficient attention to the penultimate component of the name of the International Union of Pure and Applied Chemistry?

I conclude with a grateful acknowledgement to friends in Paris, Johannesburg and Mount Isa whose willing cooperation, so typical of the mineral industry, has made this presentation possible.

\section{REFERENCES}

${ }^{1}$ M. Mottley. 'Strategic planning and mineral policy formulation'. (Address to Institute of Management Sciences, Cleveland, Ohio, 12 September 1968).

2 P. M. D. Bradshaw and A. J. Stoyel. Inst. Mining Met. Trans. Sect. B, 77, B144 (1968).

3 J. H. McCarthy, Jr, W. W. Vaughn, R. E. Learned and J. L. Meuschke, U.S. Geol. Surv. Circ. No. 609 (1969).

${ }^{4}$ D. R. Derry. Mining Mag. 120, 151 (1969).

5 W. G. Garlick. 'Proceedings-General'. Eighth Commonwealth Mining and Metallurgical Congress (1967), $p$ 1393. Melbourne.

6 J. D. Ridge, 'Ore deposits of the United States, 1933-1967', p. 1713. American Institute of Mining, Metallurgical and Petroleum Engineers: (New York) (1968).

7 K. C. Dunham, Econ. Geol. 59, 1 (1964). 


\section{MINERALS: PROSPECTING, PROCESSING AND PRODUCTION}

${ }^{8}$ H. F. King and B. P. Thomson. 'Geology of Australian ore deposits. Fifth Empire Mining and Metallurgical Congress, 1st ed., p 533. Melbourne (1953).

9 H. F. King. 'Gcological significance of stratiform ore deposits'. (Address to 15th InterUniversity Geological Congress, Leicester, U.K., 18 December 1967).

10 W. M. B. Roberts. 'Proceedings-General'. Eighth Commonwealth Mining and Metallurgical Congress (1967), p 1269. Melbourne.

11 H. F. King. Australian Mining, 60 (2), 41 (1968).

12 B. Bubela and J. A. McDonald. Nature, Lond., 221, 465 (1969).

13 J. L. Bischoff and F. T. Manheim. 'Economic potential of the Red Sea heavy metal deposits'. (Pre-publication data, 1969).

14 D. E. White. Econ. Geol. 63, 301 (1968).

15 W. S. Rapson. 'Proceedings-General'. Eighth Commonwealth Mining and Metallurgical Congress (1967), p 257. Melbourne.

16 R. L. Hewett. Australas. Inst. Mining Met. Proc. 226, 73 (1968).

17 G. M. Lukaszewski. Australas. Inst. Mining Met. Proc. 228, 61 (1968).

18 B. L. Cusak. Australas. Inst. Mining Met. Proc. 224, 1 (1967).

19 J. T. Woodcock and M. H. Jones. Ninth Commonwealth Mining and Metallurgical Congress (London) (May 1969), Preprint 4, Mineral Processing and Extractive Metallurgy Section.

${ }^{20}$ T. W. Healy. University of Melbourne: Research report to Australian Mineral Industries Research Association (June 1969).

21 C. G. Maier and O. C. Ralston. J. Amer. Chem. Soc. 48, 364 (1926).

22 M. R. W. Rey. Rev. mét. 33, 295 (1936).

${ }^{23}$ C. Rampacek, W. A. McKinney and P. T. Waddleton. U.S. Bureau of Mines, Rep. Invest. No. $5501(1959)$.

${ }^{24}$ F. Pollandt and M. E. Pease, Bull. Int. Mining Metall. No. 646, 687 (1960).

${ }_{25}$ H. Schäfer anL K. Etzel. Z. Anorg. Allgem. Chem. 291, 294 (1957).

${ }^{26}$ C.-H. Wong anL V. Schumaker. J. Phys. Chem. 61, 358 (1957).

27 E. T. Pinkney and N. Plint. Inst. Mining Met. Trans. Sect. C, 76, C 114 (1967).

${ }^{28}$ F. D. Richardson. Inst. Mining Met. Trans. Sect. C, 76, C 293 (1967).

29 M. R. W. Rey. Inst. Mining Met. Trans. Sect. C, 76, C101 (1967).

${ }^{30}$ F. D. Richardson. J. Iron Steel Inst. 203, 217 (1965). 